\title{
Syntactic focus marking in Khoekhoe ("Nama/Damara")
}

\author{
Wilfrid H. G. Haacke \\ University of Namibia
}

Khoekhoe syntax exhibits an unusually flexible constituent structure. Any constituent with a lexical head can be preposed into the focal initial slot immediately before the PGN-marker that marks the subject position. Two strategies of focalisation by foregrounding need to be distinguished: inversion and fronting. Inversion amounts to an inversion of subject and predicate in their entirety. Such sentences have two readings, though, according to their underlying constituent structure: "predicative" or "copulative". Fronting amounts to the preposing of a lexical constituent into the focal initial slot, with subsequent dislocation of the lexical specification of the subject from that slot.

The present analysis has wider implications, particularly:

The generally accepted view that Khoekhoe has coreferential/equational "copulative" sentences of the type $\mathrm{NP}_{\text {subject }}=\mathrm{NP}_{\text {complement }}$ is a fallacy. Such sentences actually are sentences with their predicate fronted into the focal initial slot. They amount to cleft constructions.

The fact that the primary focal position is immediately before the PGNmarker of the subject is further independent evidence for the "desentential hypothesis", according to which subject and object NPs in the underlying matrix sentence consist of only an enclitic PGN-marker, and for the claim that Khoekhoe underlyingly is a SVO language, not a SOV language as generally held. By implication these findings affect the analysis of other Central Khoesaan languages.

\section{Introduction}

Khoekhoe $^{1}$, which is spoken in Namibia and is the largest surviving Central Khoesaan language, exhibits a remarkably flexible constituent structure in its

1 For the sake of brevity this language, which in Namibia now is designated officially by its revived original name Khoekhoegowab ("Khoekhoe language"), is referred to here as Khoekhoe. The unitary name Khoekhoegowab avoids the undue prominence given to the 
syntax. It will be argued in this paper that this is due to the fact that Khoekhoe is a discourse-oriented language, i.e. that, subject to certain grammatical constraints, in Khoekhoe it is information-packaging devices which determine surface word order, rather than the grammatical rôles of constituents. This paper will deal with some formal strategies of information coding in Khoekhoe, rather than pragmatic issues, as pragmatically distinct types of focus (e.g. presentational vs. contrastive focus) do not appear to elicit syntactic strategies that are mutually exclusive. The paper will moreover be confined to syntactic strategies of focus marking, ignoring the use of prosodic prominence, which is often applied in the post-subjectival position of syntactically unmarked sentences.

Khoekhoe is a rheme-first type of language. Conventionally it is viewed as an SOV language. This contention is based on pragmatically least marked sentences like (1), in which the subject and object NPs are lexically specified, i.e. consist of a lexical word category, in addition to a PGN-marker:

$\begin{array}{lllll}\text { (1) } & \text { (S.TYPE) } & \mathrm{NP}_{\text {object }} & \text { TAM VERB } \\ \begin{array}{ll}\text { subject } \\ \text { man+III.M.S+NOM }+\varnothing\end{array} & \text { IND } & \text { tara }+s+a & \text { woman+III.F.S+OBL PR } & \text { see } \\ \text { 'THE/A MAN is seeing the/a woman.' } & & \end{array}$

It will be maintained in this paper, though, that Khoekhoe underlyingly is an SVO language. ${ }^{3}$ As pragmatically least marked strategy the focus allocation can vary in this canonical sentence and would be marked by stress differentiation. Depending on the pragmatic context, the subject here actually may present the thematic topic, not the focus, even though its lexical specification occupies the

ethnolects of either the Nama or Damara, and does not exclude smaller ethnicities like the Haillom, who also speak the language.

2 A list of the abbreviations used is given at the end of the paper.

3 Comparative evidence from other Central Khoesaan languages supports this claim, as in these languages post-verbal PGN-markers cross-reference to lexically specified objects before the verb; e.g. IGani (data adapted from Friederike Wilkening, unpublished handout):

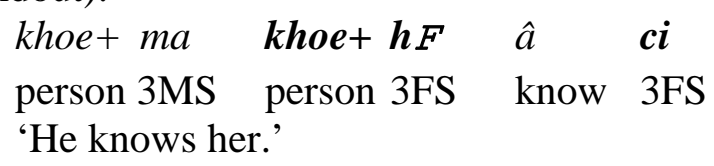

Similar examples of “object agreement” are discussed in Vossen 1985: 80-81.

In $\neq \bar{A}$ khoe too, a peripheral dialect of Khoekhoe, the lexically specified object can cooccur with the OM, e.g. Khoes ge khoe-oreba ge !gamme bi (A woman married a cannibal). 
initial slot (see below). The object could be secondary focus marked by stress. In its least marked reading this type of sentence is a presentational or eventreporting sentence with sentence-focus structure. Focus allocation that is more marked would resort to a syntactic permutation, as will be discussed.

\subsection{The desentential hypothesis}

An attempt to not merely describe but explain Khoekhoe syntax resorts to what I have elsewhere dubbed the "(de)sentential hypothesis"4. This hypothesis is amply supported by independent evidence from Khoekhoe syntax. It accounts for various phenomena in Khoekhoe syntax, some of which are, from the point of view of universal grammar, otherwise awkward to explain, e.g. the occurrence of nouns in the first and second person. The gist of this desentential hypothesis has to be repeated here before focus marking can be discussed. ${ }^{5}$

The minimal requirement for a Khoekhoe sentence is to have

- a subject NP consisting of a non-lexical pronominal element only, viz.

a PGN-marker (conventionally often referred to as "pronominal suffix"), and

- a VP consisting of (a) tense-aspect marker(s) and a lexical element as predicate head, the verbal (which can be a verb or a member of any lexical category other than adverbs or conjunctions).

This means that, per definition, there is one only (possibly complex) lexical constituent in the so-called "minimal sentence", namely the verbal (i.e. any lexical word category acting as predicate head, in the case of sentence (2) an adjective):

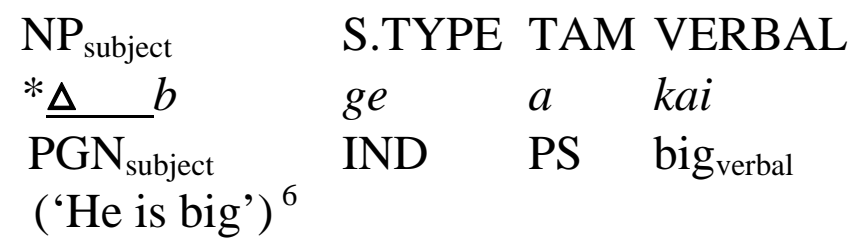

As there exists a syntactic constraint that a sentence cannot begin with a grammatical formative (viz. PGNs, sentence type markers like the indicative main clause marker ge, tense markers or aspect markers), an underlying minimal sentence with the canonical form as in (2) must have its only lexical element, the verbal, preposed into the initial slot $\Delta$, that is, the slot immediately before the

\footnotetext{
See i.a. Haacke 1992.

This resumé in section 1.1 is essentially repeated from Haacke (forthc.).

6 To simplify the schematic presentations the PGN-marker $b$ (he) for the III.M.S is further on simply glossed as "PGN", when opportune.
} 
subject-PGN. The initial slot is the primary focus position, unless the subject and predicate of the sentence are "inverted" (see (10a), (11a) in section 2.1). ${ }^{7}$ The constituent structure of (2), viz. PGN TAM VERBAL, can only surface as non-minimal sentence; that is, when an additional lexical element is inserted into the initial slot $\Delta$ via an underlying clause, to be discussed shortly ((6a)). Accordingly two surface strategies are possible for the minimal sentence:
Kai $\boldsymbol{b}$
(ge) a
$=$ PREDICATIVE reading
big PGN IND PS
'He is big.'

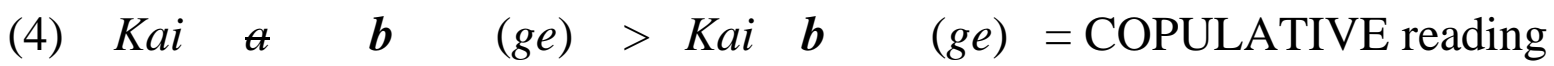 big PS PGN IND big PGN IND 'He is a big one.'

The difference in the readings of these two strategies is pivotal to Khoekhoe syntax:

The reading of sentence (3) is PREDICATIVE, since the representative of the predicate, the TAM - here the present stative $\boldsymbol{a}$, still stands to the right of the subject, as it does also in the underlying minimal sentence (2). The subject-NP here consists of the minimally required constituent: a PGN only ( $\boldsymbol{b}=$ "he"). The subject-PGN is the peg around which Khoekhoe syntax is structured grammatically. Sentence (4), where the TAM $\boldsymbol{a}$ has been preposed to the left of the subject (into the initial slot $\Delta$ together with the obligatorily preposed verbal), receives a so-called COPULATIVE reading, that is, a nominal reading of the type "X be $\boldsymbol{a ( n ) / t h e ~ Y " . ~ T h i s ~ n o m i n a l ~ r e a d i n g , ~ w i t h o u t ~ t h e ~ I N D ~ g e , ~ i n ~ K h o e k h o e ~}$ forms the grammaticalised surface form of nouns in nominative/citation form, consisting of a "stem" (the lexical specification (LS)) and a PGN:

\section{\#[lexical specification]+PGN\#. ${ }^{8}$}

The present stative aspect marker $a$ (but no other TAM!) is, as a rule, deleted in the COP strategy (indicated by "strikeout" appearance in (4)). Hence structure (4) is the source of the surface nominal kai.b (big one), which actually is a pronominally used adjective. The fact that surface nominals are not followed by

7 Sentences where the initial slot is occupied by a conjunction or the hortative particle $A$ will not be discussed here, as this topic would divert too far into pragmatic issues. In such cases, focus appears in a post-subjectival position, similar to those of the unmarked strategy of sentence (1).

8 The term "lexical specification" is used here in a non-theoretical sense. It can be a nominal stem and/or any type of qualifier.

9 A full stop is occasionally used for explicatory purposes to separate the stem of a nominal from its PGN. 
a case marker is here, for the sake of expedience, occasionally expressed by stipulating a NOM zero case marker $(\varnothing)$.

If the adjective that for the purpose of explication was here used as verbal (sentences (2) - (4)) is now replaced in the nominal reading with a noun (root/stem) (cf. equivalent sentences (2a) - (4a)), it should be apparent why Khoekhoe surface (!) "nouns” are said to consist of a \#[stem]+PGN\#:
a. $* \underline{\Delta b}$
ge
$a$
!ûi-ao
PGN
IND
PS
herd+man
('He is herdsman')

(3) a. !U Ui-ao $\boldsymbol{b}(\mathrm{ge}) \boldsymbol{a}>\{[! \hat{U} i-a o] \boldsymbol{b}\} \boldsymbol{a} \quad$ PREDICATIVE $>$ oblique case ('He is herdsman') herdsman+PGN+OBL
a. !Ûi-ao a $\boldsymbol{b}($ ge $)>$
$\{[! \hat{U i}$-ao $] \boldsymbol{b}\}$ COPULATIVE $>$ nominative case ('He is a/the herdsman') herdsman+PGN

The seemingly awkward occurrence of Khoekhoe "nouns" in the first or second person is even predictable now:
!Ûi-ao a,- $\quad$ ta
(ge) $>\{[! \hat{U i}$-ao $]$ ta $\}$
('I am a herdsman')
herdsman+I.S
('I, a herdsman')

The above two syntactic strategies occur with any of the lexical word categories (as well as some phrasal constituents like simple possessive NPs or relative clauses) when serving as verbal, here illustrated with the COPULATIVE strategy in which the present stative marker $a$ is elided:

\begin{tabular}{|c|c|c|c|}
\hline adjective: & Kai a b ge & $>\quad\{[\boldsymbol{k a i}] b\} \varnothing$ & (the/a big one) \\
\hline demonstrative: & Nēe $a$ ge & $>\{[\boldsymbol{n} \overline{\boldsymbol{e}}] b\} \varnothing$ & (this one $=$ this) \\
\hline article: & $\| \hat{I}$ a b ge & $>\{[/ / \hat{\boldsymbol{i}}] b\} \varnothing$ & $\begin{array}{l}\text { (the said/discussed } \\
\text { one = he) }\end{array}$ \\
\hline cardinal numeral: & /Gui a b ge & $>\{[$ Igui $] b\} \varnothing$ & (the one $=$ one) \\
\hline ordinal numeral: & !Nonallî $\mathrm{a} b$ ge & $>\{[$ !nona/li $] b\} \varnothing$ & $\begin{array}{l}\text { (the third one }=\text { the } \\
\text { third) }\end{array}$ \\
\hline possessive: & Ti $a b g e$ & $>\{[\boldsymbol{t i}] b\} \varnothing$ & $($ my one $=$ mine $)$ \\
\hline & Khoe.s di a $b$ ge & $>\{[$ khoe.s di $] b\} \varnothing$ & $\begin{array}{l}\text { (the one of the/a } \\
\text { woman = the/a } \\
\text { woman's) }\end{array}$ \\
\hline
\end{tabular}




\section{verb (rel. clause): $\overline{\boldsymbol{I}}$ range $\quad>\{[\bar{i}$ ra $]$ n $\} \varnothing$ $=$ \\ noun (stem) (!): Nama a b ge $\quad>\{[$ Nama $] b\} \varnothing$ \\ (they which happen happenings) \\ (the/a Nama one $=$ the/a Nama (man))}

If the verbal belongs to one of the lexical categories adjective, demonstrative, article, numeral or possessive (phrase), it acts as "qualifier" in the copulative strategy; if the verbal is a verb, then its TAM cannot be deleted in the copulative strategy and the phrase is a relative clause, i.e. another type of qualifier; if the verbal is a noun (root/stem), the surface construction yields a (surface) "noun" with the structure \#[stem]+PGN\#.

As pointed out before, in the copulative strategy we are dealing with the pronominal usage of these verbals, as also exemplified in (4) above. The pronominal usage of the so-called "pronoun stem" (here called an article) - is what is fallaciously considered to be the "full form" of the "pronoun" ${ }^{10}$ The above example with the verb $\bar{i}$ (happen, occur) is, per definition (see below), a pronominally used relative clause, as the present continuous aspect marker $r a$ cannot be elided. In practise, however, this pronominal relative clause $\bar{r} r a . n$ is perceived to be a (phrasal) noun.

$\mathrm{Be}$ reminded that a relative clause is taken to be any qualifier (for explicatory purposes included in parentheses (...) that contains a predicate. A predicate, in turn, is identified by having (a) tense-aspect marker(s) in addition to the verbal. An attributively used relative clause precedes the antecedent noun (terminated by a PGN); a pronominally used relative clause is terminated by the PGN of the (omitted) referent. Thus, in $\{[(\boldsymbol{k a i}) \mathrm{ao}] \mathrm{b}\}$ (a big man) the qualifier consists solely of the adjective kai; in $\{[(\boldsymbol{k a i} \boldsymbol{a})$ ao]b $\}$ (a man who is big) the qualifier consists of a relative clause with a TAM ( $a$ ) and an adjective serving as predicate head/verbal. According to the strategy illustrated in (4) above, a pronominally used relative clause (i.e. without an antecedent) thus has a COPULATIVE/(pro)nominal reading, as the TAM stands to the left of the subject-PGN: $\{[(\boldsymbol{k} \boldsymbol{a i} \boldsymbol{a})] \mathrm{b}\}$ (a big one).

The PGN (called "nominal designant" in earlier writings of mine) is the true pronoun of Khoekhoe. It is not a suffix as usually claimed, albeit clitic. As pro-form it can on its own constitute a NP in a sentence. Two variants of the PGN occur: the subjectival PGN (also occurring as so-called nominal "suffix", as above) and the objectival PGN. In the objectival PGN, here called object marker (OM), a latent $-i$ surfaces in the non-syllabic PGN-markers (tsi, si, bi)

10 For further discussion see Haacke (forthc.). 
and the first Person singular marker $\left({ }^{*} t a+i>t e\right) .{ }^{11}$ OMs are postclitics too, but follow immediately on the verb. Minimal sentences (i.e. with one only lexeme, viz. the verbal) thus can have an objectival argument, as long as it is not lexically specified:

(6)

$\begin{array}{lllcr}{ }^{\Delta} \boldsymbol{b} & (g e) & \text { go } & \text { mû } & \text { si } \\ \mathbf{P G N}_{\text {subject }} \text { IND } & \text { RP } & \text { see }_{\text {verb }} \mathbf{O M}_{\text {object }}\end{array}$

'He saw her.'

If subject-NP and/or object-NP are to be lexically specified, this is done by embedding a (minimal) sentence that elaborates on the reference of the subjectPGN or OM of the main clause (see (6) above for glosses). Such embedded clauses surface in either nominative or oblique strategy, as depicted in (2a) (4a):

(6) a. *



he PS Peter b ge

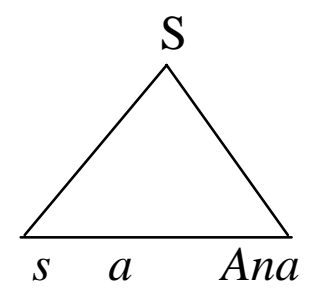

she PS Anne go mû si

(Underlying SV structure; cf.

(2))

(6) $b$
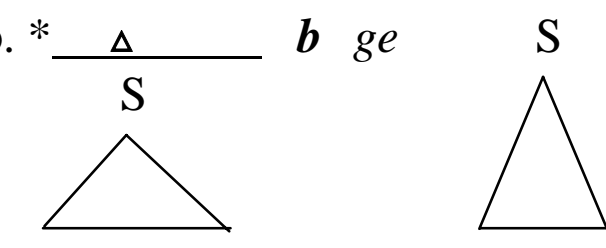

Petru $\boldsymbol{a} b_{\text {nominative }}$

Ana s a $a_{\text {OBLIQUE }}$

go mû

si

(Fronting into $\Delta$ of predicate and verbal respectively; cf. (4) a. and (3) a.)

(6) $c$

$\begin{array}{lllll}\{[\text { Petru }] \boldsymbol{b}\} \varnothing_{\text {subject }} & \text { ge } & \{[\text { Ana }] \mathrm{s}\} \boldsymbol{a}_{\text {object }} & \text { go } & \text { mû } \\ \text { Peter } & \text { IND } & \text { Anne } & \text { RP } & \text { see }\end{array}$

'Peter saw Anne.'

11 In northern, Haillom and $\neq \bar{A}$ khoe dialects this latent vowel sporadically surfaces also in the subject-PGN; e.g. $\neq \bar{A}$ khoe: Mati go a hîo o si soresa fgâ? ('How did she - the sun set?'). 
In Khoekhoe, thus, the lexical specification of any NP is entered as clause underlyingly, as illustrated above:

The lexical specification of the subject in a declarative sentence is entered in the COPULATIVE/nominative strategy (NOM, with deletion of the stative aspect marker $a$ and equi-deletion of the embedded PGN). ${ }^{12}$ All other core arguments (that is, subjects of questions, deposed subjects and objects) surface in the PREDICATIVE/oblique strategy (OBL) and thus retain their sentential nature. No equi-deletion takes place, as they do not surface in the slot of the surface PGN or the OM, whichever the case may be. In the case of the object, the lexically specified NP does not appear in the postverbal slot of the OM but is preposed, usually to the position immediately before the TAM, while the OM is deleted, as evident from (6a)-(6c).

As the clitic OM (the true pronoun!) always succeeds the verb, it follows that underlyingly Khoekhoe is not a SOV language but SVO; cf. the matrix sentence (6).

\section{2 “Copulative" sentences}

Before focus marking can be discussed, the reader also needs to be introduced to what traditionally is known as "copulative" sentences. Two types are distinguished (all examples are confined to indicative matrix sentences):

\section{Simplex Copulative Sentences (SCS) with the structure $\{\mathrm{NP}\} \varnothing$ ge, e.g.}

(7) $\quad\{[$ !Khodao-ao $] b\} \varnothing$ ge 'He is a/the tracker.';

cf. also sentences (4) and (5) above.

Coreferential Copulative Sentences (CCS) with the structure $\{\mathrm{NP}\} \varnothing$ ge $\{\mathrm{NP}\} a$, e.g.

(8) $\quad\{[$ !Khōdao-ao $] b\} \varnothing$ ge $\{[$ Nama $] b\} a$ '?The tracker is a Nama.'.

The conventional translations of the CCSs (8) and (8a) are provisional, as their validity will be questioned below (Section 3). In both types of copulative

12 In Naro, a Central Khoesaan language from Botswana, lexically specified subject-NPs of indicative sentences also appear in the oblique case; e.g. Marysa ko nquu.ba tshao ('Mary is building a house'). Cf. Haacke (forthc.). 
sentences, the NPs can be extended with attributive or appositive qualifiers (here identified by parentheses); e.g.

(7) a. SCS:

$\{[($ Xamre ra) !khōdao-ao $]$ b $\} \varnothing \quad$ ge lion-look-for PR take-track-man+IIIMS+NOM IND 'He is a tracker looking for lion.'

a. CCS:

$\{[($ Xamre $\quad$ ra) $)$ !khōdao-ao $] \boldsymbol{b}\} \varnothing \quad$ ge $\{[($ !amsa $)$ Nama $] \boldsymbol{b}\} a$ lion-look-for PR tracker+IIIMS+NOM IND brawny N.+IIIMS+OBL ?'The tracker who is looking for lion is a brawny Nama.'

Attributively used qualifiers stand before the noun; appositively used qualifiers follow the noun with a resumptive PGN but need not be discussed here. It should be remembered that attributive qualifiers (in parentheses (...)) form part of the lexical specification (in square brackets [...]) of a noun phrase. The reading of sentences like (7a) can be ambiguous though, as will be shown imminently (section 2.1).

Now that the structures known as "copulative" sentences have been introduced, syntactic perturbations can be examined with regard to focalisation.

\section{Syntactic perturbations in Khoekhoe}

Of the few constraints that pertain to Khoekhoe word order, only two concern us here:

A surface sentence cannot commence with a grammatical formative, in particular, not with PGNs or TAMs; e.g. (6) above;

A lexically specified object may not appear in front of a lexically specified subject (unless the entire predicate appears in front of the lexically specified subject, as in (11) a.), e.g.

$\begin{array}{lcccc}\text { *[Tara }] \text { sa } & {[\boldsymbol{a o}] \boldsymbol{b} \emptyset} & \text { ge } & \text { ra } & \text { mû. } \\ \text { woman+III.F.S+OBL } & \text { mabject } & \text { man+III.M.S+NOM } \\ \text { 'Thubject } & \text { IND } & \text { PR } & \text { see } \\ \text { 'The/a man is seeing the/a woman.' } & & \end{array}$

Syntactic devices are the most explicit means to mark focus in Khoekhoe; morphological markers are not employed, and stress or intonation are of secondary significance, not to be discussed here. A tonological device is employed in interrogative sentences (cf. section 4). As said before, Khoekhoe is a rheme-first language, i.e. if syntactic focus marking is resorted to, then the 
salient information is foregrounded to the beginning of the sentence in one of two ways, to be discussed imminently.

As was demonstrated in sentence (1) (here elaborated on as (10)), the primary focus position normally - but not always - is in the initial slot $\Delta$ immediately in front of the subject-PGN (underscored in (10)) ${ }^{13}$ :

(10)

\begin{tabular}{lllll}
$\Delta \quad \mathrm{PGN}_{\text {subject }}$ & (S.TYPE) & $\mathrm{NP}_{\text {object }}$ & \multicolumn{2}{c}{ TAM VERB } \\
$\{[$ Aoo $] b\} \varnothing$ & ge & $\{[$ tara $]$ s $\} a$ & ra & mû \\
man+III.M.S+NOM & IND & woman+III.F.S+OBL PR & see \\
('THE/A MAN is seeing the/a woman') & &
\end{tabular}

"Primary" focus should be understood here as position for most explicit focus marking, not necessarily as most frequently used position. Alternatively, the focus in this syntactically unmarked construction could also be on the object (by prosodic prominence), or it could be sentence-focus in an event-reporting context. This pragmatic matter is not to be pursued here. (The reader may pardon the rather unimaginative example sentence, which was chosen in order to avoid clicks.)

Two strategies of focalisation by foregrounding need to be distinguished: here called inversion and fronting. Inversion requires a lexically specified subject in the subject slot. During inversion the order of Subject and Predicate in their entirety is simply inverted to Predicate - Subject, without that the (lexically specified) subject itself is affected. During fronting, however, the focalised constituent is advanced into the focus slot immediately before the subject-PGN, which - crucially - results in the deposition of any LS of the subject, if present.

For the sake of simplicity most examples of permutations will be based on example (10), the pragmatically least marked structure.

\subsection{Inversion}

The inverted version of sentence (10) (here without object) is
a. VERB TAM
$\Delta$ PGN $_{\text {subject }}$
S.TYPE
Mû
ra
$\{[a o] b\} \varnothing$
ge
see
PR
man+III.M.S+NOM
IND
('The man IS SEEING/DOES SEE') = PREDICATIVE reading

\footnotetext{
13 As should emerge from the further discussion, the claim in Hagman (1977: 108) that "the initial position [is] the position before $g e$ in a declarative sentence" cannot be sustained.
} 
As the sentence cannot commence with a grammatical formative, the TAM and VERB are inverted within the preposed predicative so as to comply with the said constraint. This sentence would be either a felicitous affirmative or informative response to the questions "Does the man see?" or "What does the man do?" respectively. In the above, predicative reading only the noun stem "ao", not "Mû ra ao", is in the initial slot $\Delta$. In this strategy the initial slot accommodates the subject specification as theme, while the preposed predicate has been placed in focus. For this reason the initial slot should not be taken to be the sole focus position: In inverted sentences like (10a) the focalised predicate (without its S.TYPE marker) is preposed into a position preceding the initial slot.

This syntactic concatenation, however, is ambiguous as it has an alternative, copulative reading, depending on the derivational history of the constituent structure of the sentence:

b.

$\begin{array}{rll}\Delta & \text { PGN }_{\text {subject }} & \text { S.TYPE } \\ \{[(\text { Mûra }) & \text { ao }] b\} \varnothing & \text { ge }\end{array}$

('He is a/the SEEING MAN/He is a MAN WHO SEES')

$=$ COPULATIVE reading

This sentence is an extended simplex copulative sentence of the type presented in (4) and (7a), "extended" with a qualifier, viz. the relative clause mû ra (who is seeing). If this qualifier consists of a relative clause, i.e. has a TAM as in (10b), then the reading is ambiguous. The entire lexical specification consisting of the noun stem with qualifier occupies the initial slot $\Delta$ in (10b) (as underscored) and thus constitutes the focus.

While sentence (10a) has a predicate-focus structure, (10b) has an argument-focus structure on the surface.

Corresponding versions of (10a) and (10b) with object also occur:

(11) a. $\quad \mathrm{NP}_{\text {object }}$

$\{[$ Tara $]$ s $\} a$

woman+III.F.S+OBL

'The man IS SEEING A/THE WOMAN' = PREDICATIVE reading
TAM VERB $\Delta$ PGN $_{\text {subject }} \quad$ S.TYPE

ra mû $\{[a o] b\} \varnothing \quad g e$

PR see man+III.M.S+NOM IND 


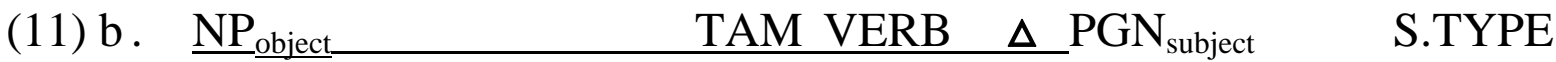

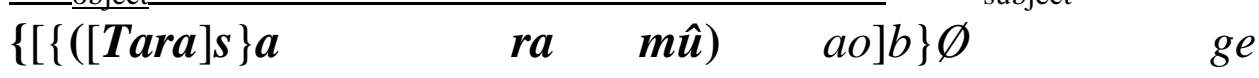 woman+III.F.S+OBL PR see man+III.M.S+NOM IND 'He is a/the MAN WHO IS SEEING A/THE WOMAN' $=$ COPULATIVE reading

In the PRED reading (11a) the entire predicate (tarasa ra mû) is rhematic. As in (10a), the initial slot in (11a) accommodates only the subject specification (ao), which is thematic. In the COP reading (11b), however, the entire lexical specification (tarasa ra mû ao) is in focus, which - in line with the minimal sentence (4) - is the (complex) fronted predicate head.

Within a preposed predicate the word order is free again, subject to the constraint that a sentence cannot commence with a grammatical formative. This facility allows for further differentiation of salience within the predicate focus, with most emphasis on the initial element within the fronted predicate. Again, both PRED and COP readings are possible. A variant of predicative (11a) would thus be (12a), and of copulative (11b), (12b):
(12) a.
VERB TAM $\mathrm{NP}_{\text {object }}$
Mû ra $\quad\{[$ tara $]$ s $\}$ a
$\frac{\Delta}{\{[a o] b\} \varnothing}$ PGN $_{\text {subject }}$
S.TYPE
see PR woman+III.F.S+OBL man+III.M.S+NOM IND
('The man DOES SEE A/THE WOMAN') = PREDICATIVE reading
(12) b.

\begin{tabular}{llll} 
VERB TAM & $\mathrm{NP}_{\text {object }}$ & $\Delta \mathrm{PGN}_{\text {subject }}$ & S.TYPE \\
\hline$\{[(\boldsymbol{M} \hat{\mathbf{u}} \boldsymbol{r a}$ & $\{[$ tara $] \boldsymbol{s}\} \boldsymbol{a})$ & $\boldsymbol{a o}] b\} \varnothing$ & $g e$
\end{tabular}
see PR woman+III.F.S+OBL man+III.M.S+NOM IND
('He is a/the MAN WHO DOES SEE A/THE WOMAN')
$=$ COPULATIVE reading

To summarise: In inversion, the full predicate is preposed to a position that precedes the underlying initial slot and is thereby placed into focus, while the lexical specification of the subject, which is in the underlying initial slot, is only presuppositional. Inversion takes place between the subject and predicate in their entirety. Preposing of a predicate complement alone, that is, of an object or adverbial phrase to a position before the lexically specified subject amounts to a violation not of inversion but of fronting, as should become clear imminently. 


\subsection{Fronting}

With fronting I refer to the preposing of a constituent other than the LS of the subject into the (underlying) initial slot $\Delta$. Since in the least marked communicative strategy the LS of the subject occupies the initial slot (sentence (1)), the preposing of another constituent into the initial slot for focalisation causes the displacement of the LS to a non-focal position. This is plausible, since pragmatically two constituents cannot vie simultaneously for prime focus status. Diagnostically: fronting causes "subject deposition" "14; inversion does not. Subject deposition means dislocation of the lexical specification of the subject, if present, to a position outside the initial slot (doubly underscored in (13)). Normally this subject specification is right-detached to the first slot available in the sentence, viz. to a position immediately behind the sentence type marker (S.TYPE, ge for the IND), which itself follows immediately on the PGN of the subject of the matrix sentence. Cf. (13), in which the object of (10) has been fronted to focus position (bolded):

\begin{tabular}{lllll}
$\Delta \mathrm{PGN}_{\text {subject }}$ & (S.TYPE) & $\mathrm{NP}_{\text {object }}$ & TAM VERB \\
\hline$\{[$ Ao $] b\} \varnothing$ & $g e$ & $\{[$ tara $]$ s $\} a$ & ra & mû \\
man+III.M.S+NOM IND & woman+III.F.S+OBL PR & see \\
('THE/A MAN is seeing the/a woman') &
\end{tabular}

(13)

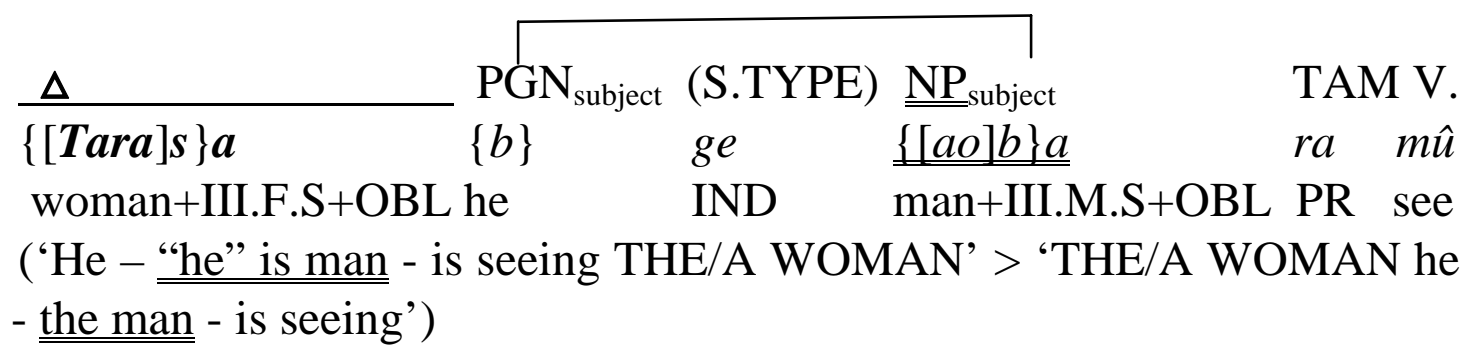

The underlying subject position in the (minimal) matrix sentence thus remains unaffected and is still occupied by the PGN $(b)$. The embedded sentence by which the LS is introduced (cf. (6) - (6c)) now has to be accommodated elsewhere. In order to maintain the coreference with the subject-PGN the PGN of this right-detached subject is not deleted by way of equi-NP-deletion but serves in an anaphoric function (here indicated by the bridge). As with all lexically specified arguments that occur in a position other than the unmarked subject position of a declarative sentence, the deposed subject now occurs in the oblique, that is, predicative form. The oblique, aptly called "Prädikatsform" already by Dempwolff (1934: 44) reflects the parenthetic sentential nature of

14 Subject deposition is investigated in more depth in Haacke (1978). 
the inserted noun phrase. As less frequent options the deposed subject may surface after the sentence as an afterthought topic ((13a), Lambrecht's "antitopic" op. cit. 203), or it may pragmatically introduce the sentence as cataphoric "attention catcher" ((13b)) by way of left-dislocation, dubbed hanging topic by Ermisch (2005: 53). As hanging topic before the sentence the subject would in Khoekhoe usually be introduced by a referential demonstrative $n \bar{e}$ or IIna (this/that previously mentioned). In both positions the extraneous status of the deposed subject would be expressed by comma intonation.

(13) a.

$\{[$ Tara $] \mathbf{s}\} \boldsymbol{a} \sim\{b\} \varnothing$ ge ra mû, $\{[a 0] b\} a$

'A/THE WOMAN he saw - the man.'

(13) b.

$$
\begin{aligned}
& \{[(/ N \vec{a}) a o] b\} a,\{[\text { tara }] \mathbf{s}\} \boldsymbol{a} \sim\{b\} \varnothing \text { ge ra mû } \\
& \text { 'That (aforementioned) man - he saw A/THE WOMAN.' }
\end{aligned}
$$

As will be apparent in the following section, virtually any constituent of a sentence that can serve as focus can be fronted into the initial slot, with concomitant deposition of the subject specification. In the case where the entire predicate is fronted, such sentences then have a surface structure that appears to consist of two NPs and hence are perceived to be "coreferential copulative sentences" of a type " $\mathrm{NP}_{1}=\mathrm{NP}_{2}$ ". It will now be argued that such "coreferential copulative sentences" amount to cleft sentences, rather, as the focal predicate has been fronted into the initial slot with subsequent subject deposition.

\section{$3 \quad$ Clefting}

It was demonstrated at some length in Haacke (1979) that the so-called coreferential copulative sentence is not a verbless sentence of the type "NP1 $1_{\text {subject }}$

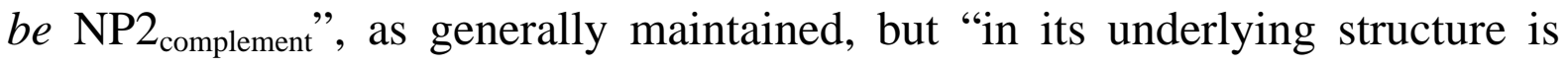
nothing but a minimal copulative sentence ('NP1') with a lexically specified subject ('NP2') that is deposed" (op.cit.: 87). If the entire predicate (or constituent following the sentence type marker) is fronted, the normal position of the deposed subject immediately after the sentence type marker (for IND: ge) in default of any other constituent turns out to be in the sentence-final position; cf. (17a). It should be remembered that both surface "NPs" underlyingly are sentences, each with its own verbal. It is for this reason that it is claimed that the CCS amounts to a cleft construction, for as part of the information packaging process, the original topic-comment sentence has been divided into two separate sections, each with its own verbal. The presence of the two surfaceNPs has, however, by analogy to Bantu led to the wrong assumption that the 
sentence-final NP, the deposed subject, is a "complement" in an "equational" sentence, sometimes called identifying copulative.

This established perception first struck me as misguided in 1975 when my late colleague and co-author of school primers, Johannes Boois translated the reply to the content question "What kind of vessels are these?" freely as

$$
\begin{aligned}
& \{[/ / \mathrm{Hoe}] d i\} \varnothing \quad \text { ge } \quad\{[(\text { ne })] d i \quad[(\text { hoa })] d e\} \\
& \text { wooden vessel+III.F.P+NOM IND this+III.F.P all+III.F.P+OBL } \\
& \text { 'They are //HOE/WOODEN VESSELS, all (of) these.' }
\end{aligned}
$$

instead of providing the expected item-for-item “equational” translation:

$$
\begin{aligned}
& \{[(\mathrm{Ne})] d i[(\text { hoa }] d i\} \varnothing \text { ge } \quad\{[/ / \text { oe }] d e\} \\
& \left(*[\text { All these }]_{\text {subject }} \text { are }\left[{ }^{\prime} / / h o e^{\prime}\right]_{\text {complement }}\right)
\end{aligned}
$$

The Khoekhoe question that had prompted this reply was

$$
\begin{array}{cr}
\{[(\text { Tare }) \text { xawa!nôa }] d e\} & \{[(\text { nê })] d e\} ? \\
\text { what vessel+type+III.F.P+OBL } & \text { this+III.F.P } \\
\text { ('WHAT KIND OF VESSELS are they, these?') }
\end{array}
$$

The "NP2" in (14) ( $\{$ nèdi hoade $\})$ no doubt resumes the theme of the question (16) ( $\{$ nede $\})$ after having supplied the desired information by way of a rhematic minimal sentence (* $\Delta$ di ge a /hoe) in (the surface!) "NP1". The dislocated lexical NP2 merely clarifies the reference of the subject-pronoun (the PGN) in the so-called "NP1", the truly propositional constituent that bears the assertive focus.

The conspicuously prevalent use of so-called copulative sentences - be they simplex or coreferential - in Khoekhoe thus is motivated by pragmatic strategies of focus placement. Pragmatic requirements are also the reason why cleft sentences are used universally in in other languages, namely to identify the most salient constituent in a sentence.

The following allosentences ${ }^{15}$ of (17), which - other than (17a) essentially are instances of narrow focus. All derivations structurally are socalled "coreferential copulative sentences". They could be prompted either by content questions as informational or assertive focus, or by wrong assumptions in yes-no questions as corrective identificational focus. The respective pragmatic situations do not require distinct constructions. But some of the

15 "Allosentence" is here used in a pragmatic sense as referring to variants in focus assignment for the same basic message. It does not make a statement about the purported syntactic derivation from one underlying sentence. 
strategies have to resort to complement sentences, though, as will be explained below.

In (17a) the entire predicate has been fronted into the main clause ("NP1") in the focus slot; the subordinate clause - the so-called "complement NP2" - is the thematic deposed subject. ${ }^{16}$

Predicative sentence, least marked for focus, often thetic:

$$
\begin{array}{llllll}
\{[\text { Petru }] b\} \varnothing & \text { ge llari } & \text { hāb lkha } & \text { !āba } & \text { go !gâu } \\
\text { Peter+PGN+NOM } & \text { IND yesterday horse with } & \text { river } & \text { RP cross } \\
\text { 'Peter crossed the river on a horse yesterday.' } &
\end{array}
$$

Entire predicate fronted into initial slot as focus:

a. $\{[$ IIAri hāb Ikha !āba go !gâu $] b\} \varnothing$ ge $\{[$ Petru $] b\} a$ yesterdayhorse with river RP cross+PGN IND Peter+PGN+NOM 'He, Peter that is, CROSSED THE RIVER ON A HORSE YESTERDAY'

$>$ 'Peter CROSSED THE RIVER ON A HORSE YESTERDAY.'

(17) b.

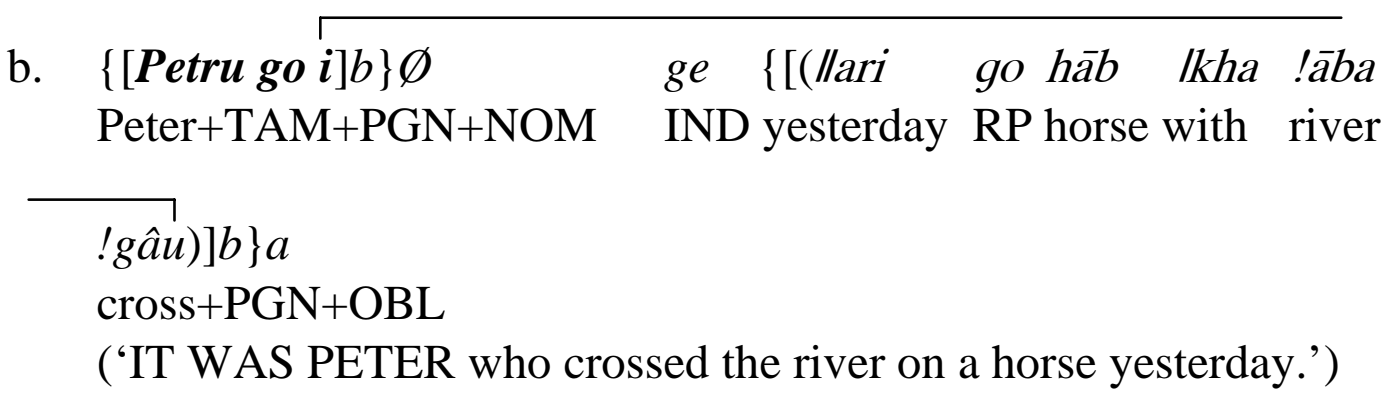

The fact that sentence (17b) concludes with a surface NP in the oblique, $\{\ldots\} a$, indicates that the agent is not in the ordinary unmarked subject position but has been fronted for emphasis.

\footnotetext{
16 A similar analysis proposed by Jackendoff (1972: 230), reiterates that in a deep structure theory "the focus is the predicate of the higher clause".
} 
Object as focus:

(17) c.

\begin{tabular}{|c|c|c|c|c|}
\hline$\{[! \bar{A}$ go i $] b\} \varnothing$ & ge & $\{[($ Petrub go & llari & $h \bar{a} b$ \\
\hline river $\mathrm{TAM}+\mathrm{PGN}+\mathrm{NOM}$ & IND & Peter & yesterday & horse \\
\hline
\end{tabular}

('IT WAS THE/A RIVER that Peter crossed on a horse yesterday.')

Adverb or adverbial phrase as focus:

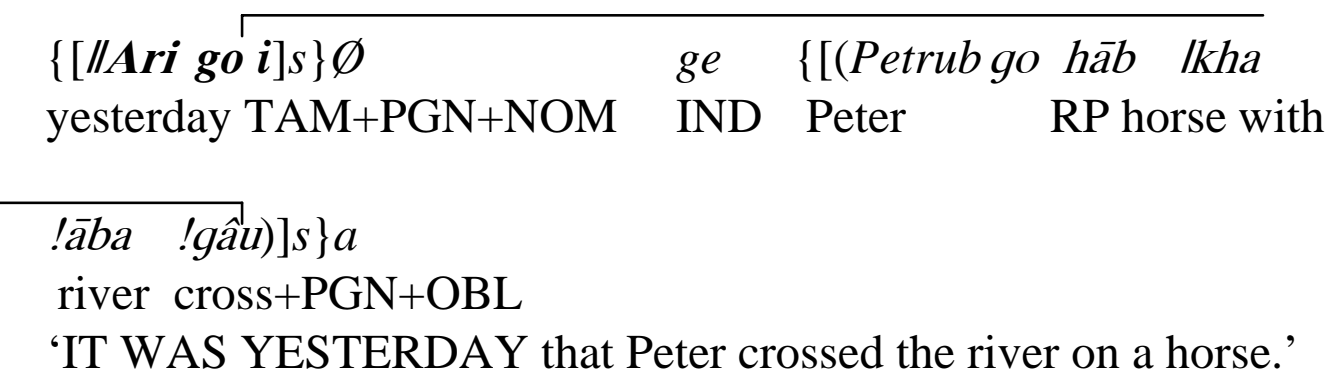

Postpositional adverbial phrase as focus:

\begin{tabular}{|c|c|c|c|c|c|}
\hline \multirow[t]{2}{*}{ (17) e. } & \multirow{2}{*}{$\begin{array}{l}\left\{\left[\begin{array}{ll}\boldsymbol{H a} \boldsymbol{a} b & \text { Ikha } \boldsymbol{g o} \text { i }\end{array}\right] \text { s }\right. \\
\text { horse with } \mathrm{TAM}+\mathrm{PGN}+\mathrm{NOM}\end{array}$} & \multirow{2}{*}{$\begin{array}{l}\text { ge } \\
\text { IND }\end{array}$} & \multicolumn{2}{|c|}{$[($ Petrub go } & Ilari \\
\hline & & & Peter & $\mathrm{RP}$ & yesterday \\
\hline & $\begin{array}{ll}\text { !āba } ! g a ̂ u)] s\} a \\
\text { river cross+PGN+OBL }\end{array}$ & & & & \\
\hline
\end{tabular}

Nominal of a postpositional adverbial phrase as focus:

\begin{tabular}{|c|c|c|c|}
\hline \multirow[t]{2}{*}{ (17) $\mathrm{f}$} & 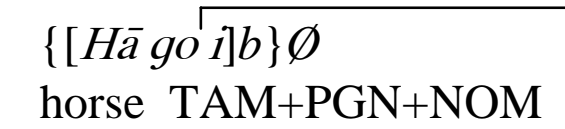 & $\begin{array}{ll}g e & \{[(/ l i \hat{b}) / k h a \sim b \\
\text { IND } & \text { he with he }\end{array}$ & $\begin{array}{l}\text { Petruba } \\
\text { Peter }\end{array}$ \\
\hline & $\begin{array}{lll}\text { llari } & \text { !āba } & \text { !gâu)]b\}a } \\
\text { yesterday } & \text { river } & \text { cross+PGN }\end{array}$ & $+\mathrm{OBL}$ & \\
\hline
\end{tabular}

Two kinds of CCSs have to be distinguished above:

- sentences in which the deposed LS is a (pronominally used) relative clause governed by the PGN of the antecedent $(b)$ in $(17 \mathrm{a} / \mathrm{b} / \mathrm{e})$; and 
- sentences in which the deposed LS is a complement clause embedded by the complementiser !khais (affair, matter). (The lexical specification!khai has been deleted in the above sentences (17d) and (17e), leaving only s.) Such complement sentences are equivalent to that-sentences in English.

The surface structure of both types is similar as both, relative clauses and complement clauses stand to the left of their head (bolded below) in attributive use, e.g.

relative clause:

< (17) b. ... \{[(llari go hāb lkha !āba !gâu) Petru $] b\} a$

'Peter, who crossed the river on a horse yesterday.'

complement clause:

< (17) d. \{[(IIAri go i) !khai]s\}Ø ge \{[(Petrub go hāb lkha !āba !gâu) !khai ]s\}a '"The matter" - that Peter crossed the river on a horse - was yesterday.'

However, the complementiser !khais is not a constituent of the input sentence underlying the complement clause; i.e. it is not relativised upon. In CCSs both types of subordinate clauses usually appear in pronominal usage; that is, the stem of the antecedent does not occur. Hence complement clauses in Khoekhoe are recognised by the feminine singular PGN $s$ of !khai.s that immediately follows the deposed clause. It may be argued that CCSs with a deposed complement sentence are analogous to pseudo-cleft sentences, rather than cleft sentences.

To conclude, so-called "coreferential copulative sentences" are sentences in which, as a process of focus assignment, the focalised constituent has been fronted into the initial slot, with subsequent right-dislocation of the lexical specification of the subject. Crucially, the entire constituent occurring after the sentence type marker (for the IND, ge) is fronted. As a result the deposed subject follows the sentence type marker as sole constituent, which makes it look like a complement-NP in a copulative sentence. But as both surface NPs underlyingly have their own verbal with TAM - cf. the nominative and oblique strategies ((3a) and (4a), such CCS constructions amount to cleft sentences which universally serve to encode information structure.

It should moreover now be evident that the CCSs

$\{[!$ Khōdao-ao $] b\} \varnothing$ ge $\{[N a m a] b\} a$ '?The tracker is a Nama.'

and 
(8) a. $\quad\{[($ Xamre ra) !khödao-ao $] \boldsymbol{b}\} \varnothing$ ge $\{[($ !amsa) Nama $] \boldsymbol{b}\} a$ '?The tracker looking for lion is a brawny Nama.'

should respectively rather be translated as "A TRACKER HE IS, the Nama > The Nama is A TRACKER" and as "A TRACKER LOOKING FOR LION HE IS, the brawny Nama $>$ The brawny Nama is A TRACKER LOOKING FOR LION".

\section{Tonal marking of focus}

Space does not allow more than a brief mention that tonal marking of focus is used in one specific case only: truth-interrogative copulative sentences. In Haacke (1979: 89ff.) it is shown with more evidence that the predicative minimal truth-interrogative sentence
(18) Kai b à?
big he PS
('Is he big?')

can optionally grammaticalise into a copulative minimal truth-interrogative sentence:
(19) $K a i+b+a ́$ ?
big + he+OBL
'Is he a big one?'

In sentence (18) the TAM $a$ is pronounced as a separate word (commencing with a glottal stop) with a low tone; in (19) - $a$ is pronounced as a suffix (without glottal stop) and a high tone. Note that the same OBL case suffix in the corresponding declarative constructions retains its low tone.

If the COP reading of (19) appears in a CCS (i.e. with deposed subject), then only the high tone on $-a$ indicates which "NP" bears the focus, as the deposed subject can be either preposed or postposed. The "NP" with the raised interrogative -á is the main clause and bears the focus:

(20) Petrubá !nari-aobà? or !Nari-aobà Petrubá?

'Is it PETER who is the thief?' > 'Is the thief PETER?'

(21) Petrubà !nari-aobá? or !Nari-aobá Petrubà?

'Is he who is Peter THE THIEF?' > 'Is Peter THE THIEF?' 
The more natural version, though, postposes the subject specification, maintaining the rheme-theme pattern as in (20). Tonology, however, overrides syntactic deposition.

Interrogative tone raising also occurs on the OBL case suffix of lexically specified subjects in predicative sentences. Cf. the correlate of (1):
$A o+b+a$
(kha) $\operatorname{tara}+s+a$
ra mû?
man+III.M.S+OBI
INT woman+III.F.S+OBL
PR see
'Does THE/A MAN see the/a woman?'

Space does not permit a discussion of focus assignment in content questions here. Suffice it to say that question words are fronted into the initial slot whenever they bear the primary focus, e.g.

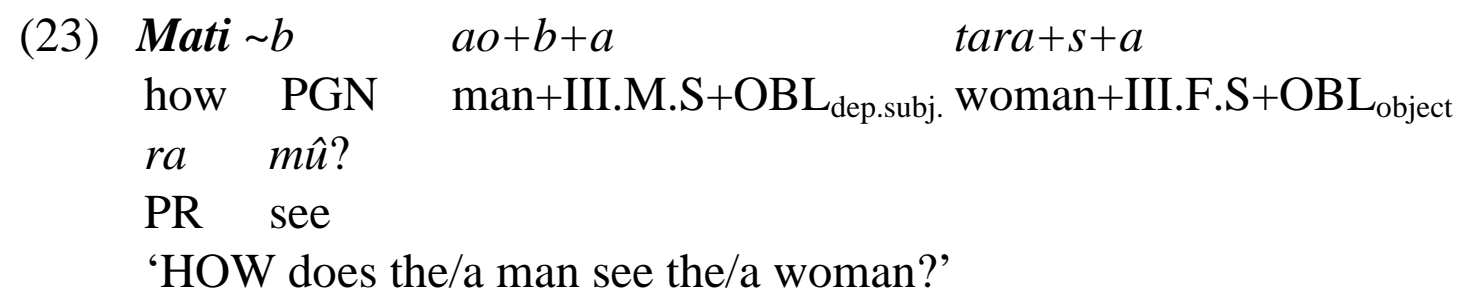

\section{Conclusion: Some remarks concerning typology}

The remarkable flexibility of Khoekhoe word order - not all grammatical sequences have been presented here - can only be accounted for if the encoding of information structure is taken cognisance of. Existing studies are confined almost solely to the description of grammatical structure. Hence two types of sentences are recognized, predicative and verbless "copulative" sentences. The desentential hypothesis, by arguing that surface nouns are derived from an underlying minimal sentence, recognises the subject and object PGNs as prime categories (pronouns) that can singly serve in subject or object function, albeit as clitics. Recognising the PGN as pivotal subject constituent accounts for the predicative and copulative readings of minimal sentences as nominative and oblique surface nominals respectively and accounts for so-called copulative sentences as special pragmatic encodings reflecting the communicative dynamism of particular constituents.

A pragmatic investigation highlights the status of the subjectival PGN as, not a suffix but an autonomous pronoun. It is significant that the subject PGN, while being postclitic, is not obligatorily suffixed to a noun stem or a word for that matter, but has to follow on a syntactic slot: the initial slot or focus position $\Delta$. Within this initial slot multiworded constituents can end with a variety of word categories as immediate antecedent to the PGN. The status of the PGN as 
autonomous category is further enhanced by the fact that sentence type markers (e.g. IND ge) have to immediately follow on the subjectival PGN, irrespective of whether there is a lexical specification present for the subject. The fact that the initial slot, being essentially a focus position, must obligatorily be filled is strong evidence that Khoekhoe is a focus-oriented language and that its word order is controlled primarily by pragmatic, not grammatical principles. ${ }^{17}$

Conversely, the fact that the focus position in Khoekhoe is defined as the position immediately before the subjectival PGN is indicative that the PGN per se, not a nominal, forms the subject NP. The same autonomous status which is assigned to the subjectival PGN must, as a matter of consistency, then be assigned to the objectival PGN or "OM". The OM appears immediately after the verb; cf. (6). (The fact that it is the same kind of pronominal word category as the subjectival PGN is the only, nevertheless decisive argument not to treat OMs as declensional suffixes of the verb.) This means that Khoekhoe at least underlyingly is a SVO language, not SOV, as generally maintained. Hence Khoekhoe does not present counter-evidence to the view that "the primary focus position in SOV languages is immediately preverbal". ${ }^{18}$ Presumably, thus, other Central Khoesaan languages are SVO languages as well.

17 According to La Polla (in Downing 1995: 14) in Chinese, like in Khoekhoe, focus structure rather than syntactic relations determine word order variation. Interestingly, this is further instantiation of typological similarity between these languages, as Khoekhoe moreover shares a considerable number of tonological traits with Chinese and other SinoTibetan languages. Cf. Haacke (1999). 


\section{Abbreviations}

CCS coreferential copulative sentence

COP COPULATIVE (structure/reading)

IND indicative main clause marker ( $g e$, follows immediately after the subject-PGN and zero NOM case marker)

INT interrogative main clause marker

F feminine

LS lexical specification (of an NP)

M masculine

NOM nominative case (Zero suffix: Ø)

OBL oblique case ( $-a$, for core arguments that are not in the NOM)

OM object marker (= post-verbal PGN)

PGN person-gender-number (marker). This postclitic formative is the true pronoun of Khoekhoe, referred to as "nominal designant" in some earlier writings of mine.

PL plural

PR (present) progressive aspect marker ( $\mathrm{ra}$ )

PS (present) stative aspect marker $(a)$. It occurs without tense marker.

PRED PREDICATIVE (structure/reading)

RP recent past tense marker (go)

SCS simplex copulative sentence

S singular

S.TYPE sentence type marker. (Khoekhoe can optionally mark matrix sentences for declarative (indicative ( $\mathrm{ge}$ ), accreditive (kom ...o)) or interrogative $(k h a)$ mood with a marker that follows immediately on the subject-PGN and zero NOM case marker.

TAM tense-aspect marker

I, II, III first, second, third Person respectively

[ ] Square brackets enclose the LS of a noun phrase, followed by a PGN.

\{ $\} \quad$ Braces enclose the all-comprising "macro-NP" (NP-bar, including appositions if present); that is, braces enclose the LS with PGN, terminated by a case marker, i.a. $\varnothing$ NOM, $a$ OBL, di possessive.

$+\quad$ A plus sign between morphemes in text or glosses indicates that the morphemes belong to one word.

$\sim \quad$ A tilde separates a PGN from a preceding morpheme with which it does not form a constituent.

$\Delta$ initial slot (primary focus position). Its domain is indicated by the underscore. 


\section{$7 \quad$ References}

Dempwolff, O. (1934/35) Einführung in die Sprache der Nama-Hottentotten. Off-print: Zeitschr. f. Eingeborenenspr. XXV: 1-3.

Downing, P. (1995) Word Order in Discourse. By way of introduction, in Downing, P. \& Noonan, M. (eds.) Word Order in Discourse. Amsterdam: John Benjamins, 1-27.

Ermisch, S. (2005) Issues in the left periphery. A typological approach to topic and focus constructions. (Doctoral Dissertation) Joh. Wolfg. Goethe University. Frankfurt.

Haacke, W.H.G. (1978) Subject Deposition in Nama. (unpubl. MA (Theor. Ling.) dissertation) Univ. Essex.

Haacke, W.H.G. (1979) Nama "coreferential copulative sentences" re-assessed, in Snyman, J. (ed.) Bushman and Hottentot Linguistic Studies (1979), Pretoria: UNISA, 80-106.

Haacke, W.H.G. (1992) Dislocated Noun Phrases in Khoekhoe (Nama/Damara): Further Evidence for the Sentential Hypothesis. Afrikanist. Arbeitspapiere, 29: 149-162.

Haacke, W.H.G. (1999) The Tonology of Khoekhoe (Nama/Damara), Quellen zur KhoisanForschung No. 16. Cologne: Rüdiger Köppe.

Haacke, W.H.G. (forthc.) Naro Syntax from the Perspective of the Desentential Hypothesis: the Minimal Sentence. Proceedings of the International Symposium on Khoisan Languages and Linguistics, Riezlern, Jan. 2003. Quellen zur Khoisan-Forschung. Cologne: Rüdiger Koeppe.

Hagman, R. (1977) Nama Hottentot Grammar. Bloomington: Indiana Univ.

Herring, S.C. \& Paolillo, J.C. (1995) Focus position in sov languages. In: P. Downing \& M. Noonan (eds.) Word order in discourse. Amsterdam: John Benjamins.

Jackendoff, R.S. (1972) Semantic Interpretation in Generative Grammar. Massachusetts: MIT.

Lambrecht, K. (1994) Information structure and sentence form. Cambridge: CUP

Vossen, R. (1985) Encoding the Object in the Finite Verb: The Case of IAni (Central Khoisan). AAP, 4: 75-84. 